\title{
Potential Use of Willingness to Accept (WTA) to Compensate Herders in Maqu County, China, for Reduced Stocking
}

\author{
Jian-Jun Cao, ${ }^{1}$ Nicholas M. Holden, ${ }^{2}$ Yan-Yan Qin, ${ }^{3}$ and Xiao-Yu Song ${ }^{4}$
}

\begin{abstract}
Authors are ${ }^{1}$ Postdoctoral Researcher and ${ }^{4}$ Doctoral Student, Cold and Arid Regions Environmental and Engineering Research Institute, Chinese Academy of Sciences, Lanzhou, China $;{ }^{2}$ Associate Professor, UCD School of Biosystems Engineering, Agriculture and Food Science Centre, University College Dublin, Belfield, Dublin 4, Ireland; and ${ }^{3}$ Aid Engineer, Research Institute of Forestry Science, Bai Long Jiang Forestry Management Bureau,

Lanzhou, China.
\end{abstract}

\begin{abstract}
In grassland areas subject to degradation caused by overgrazing such as the Maqu grasslands, excess livestock could be removed in order to balance available forage and animal numbers. As the number of animals owned by a herder family represents wealth, income, lifestyle, and culture, reducing livestock numbers is problematic and some form of compensation is required to encourage change. Willingness to accept compensation (WTA) was assessed with the use of contingent valuation (CV) methodology to estimate the value that herder families place on the livestock numbers that lead to overgrazing. The minimum acceptable compensation was estimated as $3717 \mathrm{RMB}(\sim 555)$ per head of cattle and $503 \mathrm{RMB}(\sim$ \$5) per head of sheep at 2005 prices. The total compensation required for herder families in Maqu was estimated to be between $2.5 \times 10^{8} \mathrm{RMB}$ and $3.7 \times 10^{8} \mathrm{RMB}$ at 2005 prices to reduce stocking to levels considered sustainable based on an estimate of $5 \times 10^{5}$ sheep overgrazing equivalents in 2006.
\end{abstract}

\section{Resumen}

Las aéreas de pastizal están sujetas a degradación por el pastoreo como en los pastizales de Maqu, el exceso de ganado podría ser removido con el fin de balancear la disponibilidad de forraje y el número de animales. Cómo el número de animales en posesión de una familia representa riqueza, ingreso, estilo de vida y cultura, la reducción del número de animales es un problema y una forma de compensación se requiere para llevar a cabo es cambio. La Disposición a Aceptar una Compensación (DAC) fue evaluada usando la metodología de Valuación Contingente (VC) para estimar el valor que el hato familiar tiene en el número de animales que provocan el sobrepastoreo. La compensación mínima aceptada fue estimada en $3717 \mathrm{RMB}(\sim \$ 555)$ por cabeza de bovino y de $503 \mathrm{RMB}(\sim \$ 7)$ por cabeza de oveja a precios de 2005. La compensacion total requerida por hato familiar en Maqu fue estimada entre $2.5 \times 10^{8} \mathrm{RMB}$ y $3.7 \times 10^{8} \mathrm{RMB}$ a precios de 2005 para reducir la carga animal a niveles considerados sostenibles basados en una estimación de $5 \times 10^{5}$ sobrepastoreo de ovejas equivalente en 2006.

Key Words: carrying capacity, contingent valuation, ecological compensation, grassland degradation, overgrazing

\section{INTRODUCTION}

There is around 4 billion ha of natural grassland in China, accounting for $42 \%$ of the land area. Considering grassland as a proportion of total land area, China ranks second in the world after Australia (Ren et al. 2007). Grasslands are found mainly in the arid north and northwest, in the semiarid mountain plateaus, on the Qinghai-Tibet plateau, and integrated into many other agricultural landscapes. Grasslands play an important role in livestock farming and environmental conservation (Akiyama and Kawamura 2007), but in China degradation is now a major problem; $90 \%$ of grassland is degraded in some way, with 1.3 billion ha severely degraded and about 2 million ha per year (Ren et al. 2007) becoming severely degraded. Usually, grassland degradation is reflected in biodiversity decline, reduced biomass production, increased soil erosion, and soil nutrient loss. For the purposes of this article we use degradation to refer to a decline in rangeland productivity, specifically plant biomass and vegetation cover, and subsequent increases in erosion and soil loss. In China

\footnotetext{
Correspondence: Jian-Jun Cao, Cold and Arid Regions Environmental and Engineering Research Institute, Chinese Academy of Sciences, DongGang 320, LZ, GS, China. Email: Caojj06@163.com
}

Manuscript received 1 October 2010; manuscript accepted 6 May 2012. average aboveground biomass of grasslands was estimated to have decreased from $>2000 \mathrm{~kg} \cdot \mathrm{ha}^{-1}$ in the $1950 \mathrm{~s} \mathrm{to}<1000 \mathrm{~kg} \cdot \mathrm{ha}^{-1}$ in the 1990s (Akiyama and Kawamura 2007), resulting in a decline in available grass/forage and less output per animal (Zhang 2007). This has caused some herder families to increase animal numbers to maintain income, which in turn has caused further overgrazing. Long-term overgrazing (Ma et al. 2010) and climate change are believed to be combining to drive the reduction in vegetation cover of Chinese grasslands (Akiyama and Kawamura 2007). Reducing livestock numbers has been recommended as a way to alleviate this problem. (Clements 1916; Ellis and Swift 1988). However, for those who rely on livestock, reducing numbers results in reduced development opportunities, and may affect social and cultural status (referred to as passive values by Carson et al. 2001). Therefore, a compensation scenario must be considered if such a policy were to be implemented. Compensation in environmental management terms refers to the cost of balancing any negative impacts of development and resource utilization (e.g., overgrazing due to an individual herder having too many animals, which impacts on the public as a whole) against societal functions (e.g., supporting a community with an appropriate standard of living; reasonable equality across society) and is becoming increasingly accepted as a tool in environmental 
economics (e.g., Cuperus et al. 2001; Barnthouse and Stahl 2002; Zhou et al. 2007).

Ecological compensation can be regarded as the price paid for individuals or regions to sacrifice their development opportunities in order to protect ecology and the environment (Liu et al. 2008). Generally, it can reflect the relationship of relevant groups to environment and economic benefits, and can promote equity and development between regions and social groups (Li and Tang 2009). Furthermore, ecological compensation can also be placed in a broader social-economic framework. To date, there have been no case studies on compensation values in grassland areas that play an important role in ecological conservation in China (Zhang 2007). According to Liu et al. (2008), the economic value of compensation for grassland can be defined as the economic cost of conservation assuming herder families are compensated for having fewer livestock in order to encourage ecological conservation. The objective of the article is to explore how much one-off compensation herders require for reducing livestock in Maqu grasslands in response to such a conservation policy if one were to be introduced.

\section{METHODS}

\section{Study Area}

The Maqu grassland ecosystem is about 870000 ha located Maqu County in the Gansu Province of China on the eastern Qinghai-Tibet plateau. The altitude ranges from $2900 \mathrm{~m}$ to $4000 \mathrm{~m}$ with an annual average temperature of $1.8^{\circ} \mathrm{C}$ (ranging from $-10.7^{\circ} \mathrm{C}$ in January to $11.7^{\circ} \mathrm{C}$ in July, and a growing season maxima of $23.6-28.9^{\circ} \mathrm{C}$ and 270 frost days annually. The grassland types include alpine meadow (59\%), brushy meadow $(33 \%)$, woodland meadow $<1 \%$ ), saline meadow $(<1 \%)$, swampy meadow $(6 \%)$, and upland grass $(1 \%)$ (Bu et al. 2006). Maqu contains seven villages and one town (subadministrative unit), with a population of about 40000 people. The area is almost exclusively used for grazing, generating around $1 \times 10^{8}$ RMB from animal husbandry (99\% of total agriculture income) in 2004 (data from Statistical Yearbook of Maqu 2005). The grassland area provides both local resources (forage for animals; a place to live) and acts as a natural ecological buffer and water conservation area for the Yellow River, supplying around $27 \times 10^{8} \mathrm{~m}^{3}$ to the flow per year. The Maqu has in fact been referred to as "the kidney of the Yellow River" because of its capacity to collect and provide water to the river. Over $90 \%$ of precipitation in Maqu is concentrated in the plant-growing season from June to September, and for the last $40 \mathrm{yr}$ the mean annual precipitation was $594 \mathrm{~mm}$ ( $\mathrm{SD}=89 \mathrm{~mm}$ ) (Wang et al. 2006).

Historically, herders in Maqu have been engaged in nomadic collective pastoral activities and are referred to as the "the nationality on horseback." Under long-term natural and artificial selection, the yak, Tibetan sheep, and Hequ horse have become the major livestock species that can adapt to the harsh local environment (Cao et al. 2011). In 1995, a grassland contract system was developed in Maqu. By 2003, 96\% of available pastures had been contracted to households, with 30 $\mathrm{yr}$ of use rights for fixed-term pasture (data from the Animal Husbandry Bureau of Maqu county 2005). After grassland was contracted, herder families established fenced boundaries, and theoretical stocking rates for individual family pastures were calculated by local Grassland Supervisor Stations, but sitespecific, long-term monitoring and enforcement has been less effective.

The theoretical carrying capacity of Maqu grassland has been calculated (assuming an equilibrium model approach) to be approximately $18 \times 10^{5}$ sheep equivalents (sheep and cattle) per year (data from Animal Husbandry Bureau of Maqu county 2005). Based on government figures (data from Statistical Yearbook of Maqu 2001-2007) up to 2005, animal numbers were slightly more than the theoretical carrying capacity, but by 2006 were estimated to be $5 \times 10^{5}$ sheep equivalents greater than the carrying capacity (Cao et al. 2008), which is perhaps now threatening both local living standards, as animals do not get enough to eat (Du and Hui 2001; Liu et al. 2002) and downstream areas of the Yellow River, where direct economic damage due to reduced water availability for irrigated agriculture has been estimated at $286 \times 10^{8} \mathrm{RMB}$ (Long et al. 2006). The elimination of overgrazing livestock is now urgent. To achieve buy-in by the local population a compensation mechanism must be established (Gao et al. 2004).

\section{Contingent Valuation Method: Willingness to Accept Compensation}

Contingent valuation $(\mathrm{CV})$ is a survey-based value elicitation approach that establishes the maximum amount an individual would be willing to pay (WTP) to secure changes (e.g., changes in the availability of public goods or amenities, changes in the qualities of commodities, or changes in the fixed quantities of rationed goods) or the minimum amount an individual would be willing to accept (WTA) to adopt changes. It is normally applied to nonmarket valued goods or services. Economists have been using and refining the method for well over two decades (Hanemann 1991; Hailu et al. 2000; Maharana et al. 2000; Wills 2002; Dupont 2003; Noonan 2003; Xu et al. 2003; Johnson 2006). It has been used extensively and described and reviewed elsewhere (Whittington 2004). In the case of protected areas, where the property rights of the communities in the resources are at stake or there is fear of losing access to natural resources, WTA is a good measure to estimate the value of nonmarket goods (Ambastha et al. 2007), and to weigh inhabitants' opportunity costs (Epstein 2003).

In pastoral areas of Maqu, livestock are typically regarded as the main source of income and development capital, but they also serve as insurance (e.g., animals are sold in the event of health emergencies), a fuel source (dung), a lifestyle (via employment) and a measure of social status (more livestock means more respect in the community). Therefore, only a few livestock are traded voluntarily by the herders at markets in order to get money, and herders are not willing to sell animals, including excess that are over the carrying capacity of grassland. Because herders are not willing to sell excess livestock, a nonmarket price method to estimate their value is required to evaluate the cost of a policy to encourage herders to give up livestock in order to balance forage yield and livestock numbers. With nonmarket method such as $\mathrm{CV}$, herders are offered a contingent situation, which is the possibility of a compensation for giving up livestock. 
Table 1. Bid range and interval for sheep and cattle derived following a presurvey questionnaire and pilot study in Maqu County.

\begin{tabular}{|c|c|c|c|c|c|c|c|c|c|c|c|}
\hline \multirow[t]{2}{*}{ (I) Sheep (RMB per head) } & 300 & 350 & 400 & 450 & 500 & 550 & 600 & 650 & 700 & 750 & 800 \\
\hline & 850 & 900 & 950 & 1000 & - & - & - & - & - & - & - \\
\hline \multirow[t]{2}{*}{ (II) Cattle (RMB per head) } & 800 & 1000 & 1200 & 1500 & 2000 & 2500 & 3000 & 3500 & 4000 & 4500 & 5000 \\
\hline & 5500 & 6000 & 6500 & 7000 & 8000 & 9000 & 10000 & 15000 & 20000 & - & \\
\hline
\end{tabular}

\section{Questionnaire Design and Field Survey}

The value of WTA was derived from a questionnaire that was designed to account for the difficulty most respondents would have expressing WTA directly. An anchored payment card (APC) eliciting tool was used in order to avoid starting-point bias and to establish the context in which the bids should be submitted (Cuena et al. 2004). With the use of APC, respondents are given a range of values to select from (bids). The range and interval between bids (Table 1) was established by (1) issuing an open-ended questionnaire to 30 local staff members of the authorities engaged in the protection of grassland resources, 50 local herders, and 30 master's degree graduates from the School of Life Science, Lanzhou University; (2) running a presurvey pilot with 50 herders (independent of those used for the open-ended questionnaire); and (3) interpretation of the results by experts from School of Life Science, Lanzhou University. In the preamble to the questionnaire local grassland conditions were described, the need for joint participation of local people and government to find a solution to vegetation and soil loss was explained, and the restoration approaches were described. Respondents were asked if they were either (1) willing to pay from family income each year for supporting grassland management (WTP is not considered further in this article as it is irrelevant to the WTA questions); or (2) willing to accept payment for permanently reducing herd size by one head of cattle or sheep, and if so, how much (Table 1)?

The survey was deployed to a sample of 800 families (100 questionnaires per village/town; ca. $10 \%$ of families) selected with the use of randomized cluster sampling. The interviews were conducted face-to-face to ensure a high response rate, to maintain respondent motivation, and to allow the use of graphic supplements (Carson et al. 2001; Nunes et al. 2004). In all, 525 valid questionnaires were completed between May and August 2005 and of these, 132 indicated WTA as a means of regulating livestock numbers. Direct questions on income and expenditure are socially unacceptable in Maqu; therefore an indirect calculation based on the number of animals owned, the number needed for feeding the household and thus those available for sale was used. Expenditure estimates included basic life necessities and then veterinary and forage supplement costs based on the number of animals (Cao et al. 2008).

\section{RESULTS}

\section{Socioeconomic Characteristics of the Respondents}

Only one quarter (132) of respondents chose paid compensation as a viable way to reduce stocking, indicating a general reluctance of the community to reduce animal numbers or place a value on the excess livestock. Most of the respondents were male (Table 2), reflecting the norm for head of family in Maqu. The mean age was $38(\mathrm{SD}=13) \mathrm{yr}$, ranging from 19 to $71 \mathrm{yr}, 77$ were illiterate with no formal education and only 1 respondent had a college education (Table 2). Level of education could be eliminated from the WTA analysis as an explanatory factor because most respondents had less than $3 \mathrm{yr}$ of formal education. The average income and expenditure of a family was $31513 \mathrm{RMB}$ per year $(\mathrm{SD}=27662)$ and $21295 \mathrm{RMB}$ per year $(\mathrm{SD}=13562)$, respectively. There was a wide gap between rich and poor families (Table 2), but the majority of families had a moderate income, with about half having an income below $25000 \mathrm{RMB}$ per year, which might be regarded as the minimum desirable income for the region.

Table 2. Summary of social and financial characteristics of the 132 respondents from Maqu County who were willing to accept compensation.

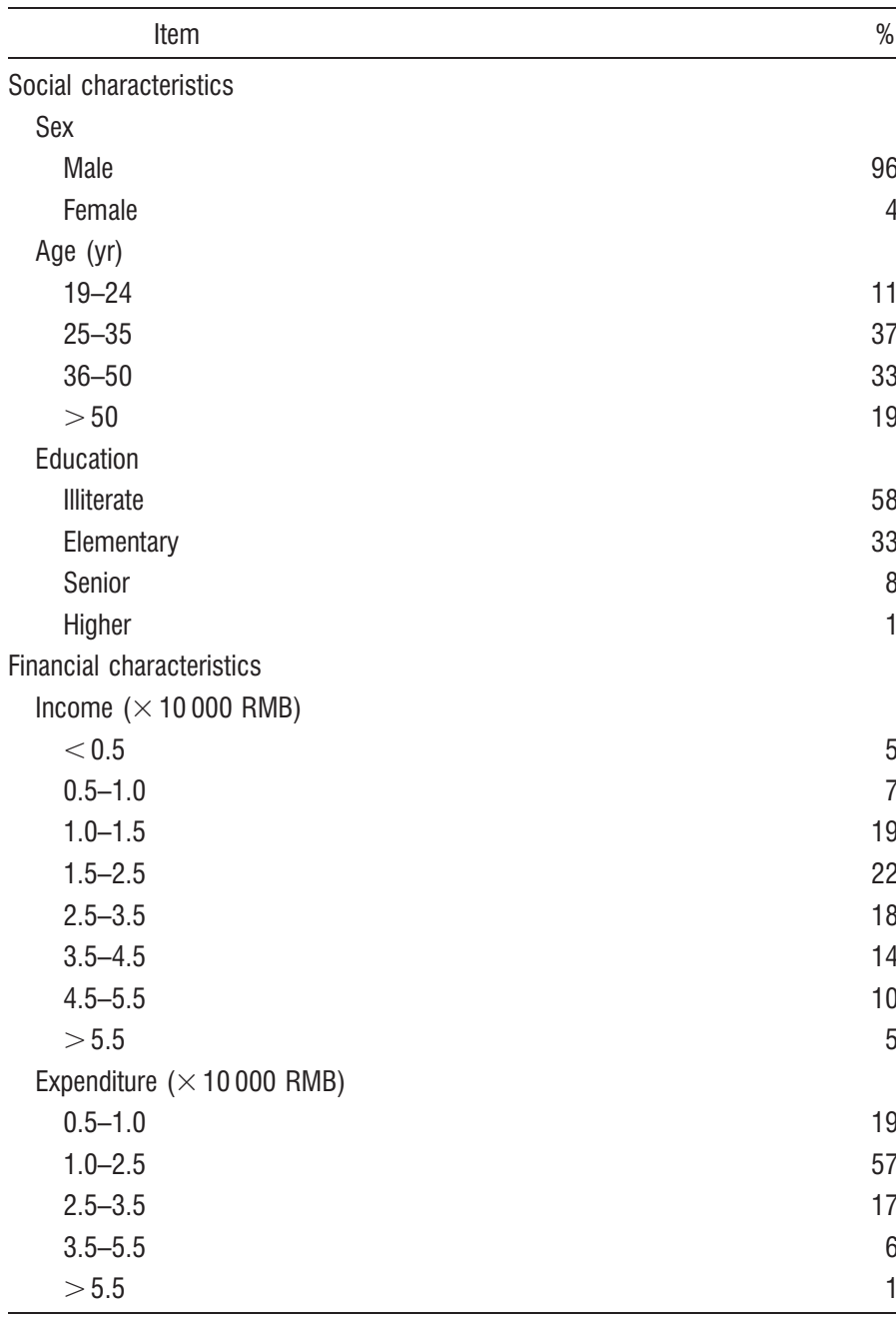


Table 3. Percentage of bid-value selection for cattle and sheep by the 132 respondents in Maqu County who were willing to accept compensation.

\begin{tabular}{ccccc}
\hline & Cattle & & & \multicolumn{2}{c}{ Sheep } \\
\cline { 5 - 5 } Bid & $\%$ & & Bid & $\%$ \\
\hline 1000 & 10.1 & 300 & 3.9 \\
1200 & 4.7 & 400 & 10.1 \\
1500 & 23.3 & 500 & 20.2 \\
2000 & 16.3 & 550 & 4.7 \\
2500 & 12.4 & 600 & 4.7 \\
3000 & 8.5 & 650 & 5.4 \\
4000 & 6.2 & 700 & 7 \\
5000 & 3.9 & 800 & 4.7 \\
10000 & 3.1 & 900 & 8 \\
20000 & 4.7 & 1000 & 24 \\
Others & 6.8 & 0 Others & 7.3 \\
\hline
\end{tabular}

\section{WTA Analysis}

A wide range of bid values was returned for both sheep and cattle (Table 3 ). Based on the bid values, the economic value of compensation for one cattle was $3717 \mathrm{RMB}$ per head (about 2.5 times of the market price of cattle in 2005) and $503 \mathrm{RMB}$ per head for sheep (about 1.4 times of the market price of sheep in 2005). About $52 \%$ of respondents selected $1500 \mathrm{RMB}$, $2000 \mathrm{RMB}$, and $2500 \mathrm{RMB}$ as the cattle bid value, indicating that half of respondents' bid values were equal or slightly higher than the market price of that time (1500 RMB per head of cattle). For sheep, $20 \%$ of respondents selected $500 \mathrm{RMB}$ and $24 \%$ selected $1000 \mathrm{RMB}$, indicating that $44 \%$ of respondents' bid values were much higher than the market price at the time (350 RMB per head of sheep). Statistical analysis revealed that age, income, and estimated expenditure could not explain WTA $\left(R^{2}=0.019\right.$ for sheep and $R^{2}=0.038$ for cattle). This indicated that WTA was probably not determined by the socioeconomic status of the herder families.

\section{DISCUSSION}

The compensation estimate derived by WTA was a nonmarket approach using CV. Although the validity and reliability of the WTA is influenced by CV questionnaire design, question order, and the difficulty of the question for the respondent (Wierstra et al. 2001; Veisten et al. 2004; Wang et al. 2006), it is still a useful tool to place value on nonmarket-valued good and services (Shechter et al. 1998; Maharana et al. 2000; Epstein 2003).

It is possible that the low rate of WTA selection (132 or $25 \%$ ) was caused by the bid design. At the bid-design stage, experts and students were consulted who perhaps limited the maximum bid using their expectation of market value rather than considering the expectation of the herders. If the bid vector was biased toward low values and herders could not see bid values close to their real WTA, then they may reject the WTA rather than accepting a value less than they require. Any future bid design for CV should avoid use of expert opinion in shaping the bid range used.
Based on the estimate of $5 \times 10^{5}$ overgrazing sheep equivalents on the Maqu grassland in 2006, and with an assumptions of stable population, no change in the theoretical carrying capacity, and the market price of livestock, at least $2.5 \times 10^{8}$ $\mathrm{RMB}$ at 2005 prices would be required to compensate herder families for reducing livestock numbers to those estimated from theoretical carrying capacity in 2006. If herder families preferred to sell old, weak, or sick animals that consume less resources and have lower value than the indicated WTA, then the compensation scheme would have to be implemented with care to monitor the type of animal and its productivity as a basis for payment. Furthermore, once compensation for reduced livestock numbers is offered, monitoring will be required to ensure that total animal numbers do not start to increase again in the future.

The estimate of $5 \times 10^{5}$ overgrazing sheep equivalents does not offer a breakdown between sheep and cattle numbers. By assuming that all the overgrazing sheep equivalents are cattle (usually one cattle $=$ five sheep in Maqu grassland), the amount of compensation would be a maximum of $3.7 \times 10^{8} \mathrm{RMB}$. Therefore, as the proportion of cattle causing overgrazing increases, greater compensation would be required. It is possible to conclude that between $2.5 \times 10^{8} \mathrm{RMB}$ and $3.7 \times 10^{8} \mathrm{RMB}$ would be required in order to reduce overgrazing livestock in Maqu grassland at 2005 prices and number of animals. Economic compensation assumes that all herder families with excess livestock would be willing to accept a one-time-only compensation payment for giving up a number of animals in a short period of time. In reality herder families will give up excess animals at different times, so the compensation values should be stable through time.

The question of who should pay compensation needs to be considered. According to Zhang (2007), the principle of ecological compensation is that those who benefit should pay. As the Maqu grassland has various ecological functions, there are a number of groups who should pay. First, the local herders can be regarded as beneficiaries, but they would not pay, as they would have already reduced livestock numbers and require compensation. The beneficiaries who might pay would be those living in the downstream areas of the Yellow River who rely on water resources and who would no longer need to invest in infrastructure protection if soil loss and runoff from Maqu were reduced. The economic loss directly attributable to the overgrazing and subsequent reduction in water conservation in the Maqu grassland can be estimated from the average economic loss of downstream areas on the Yellow River, which is around $40 \times 10^{8} \mathrm{RMB}$ per year (Long et at. 2006). Taking the Yellow River length around Maqu as $12.5 \%$ of its total length (433 km from a total length of $3742 \mathrm{~km}$ ) and using this to apportion loss, then $5 \times 10^{8} \mathrm{RMB}$ per year of economic damage was potentially caused by changes to the Maqu grasslands (Cao $2006)$. This means that the compensation $\left(2.5 \times 10^{8} \mathrm{RMB}\right.$ to $3.7 \times 10^{8} \mathrm{RMB}$ in 2005) is probably little more than half the economic damage being caused per year. According to government statistics for 2006, the GDP of the downstream areas was about $5 \times 10^{12} \mathrm{RMB}$, thus less than $0.1 \%$ of GDP would be required to finance Maqu grassland protection. However, between, 1998 and 2002 central government funds invested in Maqu were only around $2 \times 10^{7} \mathrm{RMB}$ (Gao et al. 2004); therefore there is considerable scope for compensation. 


\section{MANAGEMENT IMPLICATIONS}

In order to intervene successfully with a compensation policy that would help reverse the declines in the water conservation capacity of the Maqu grassland due to overgrazing, excess livestock could be purchased by the state for removal in order to meet the theoretical carrying capacity of the land. The funds required to achieve this should reflect the economic value perceived by herders, which is linked to their change in status due to owning less animals.

This study indicates that local communities can and will respond positively to ecological compensation provided they are consulted and given a voice during planning of such interventions and compensation makes economic and environmental sense. The study has implications for other areas of China and beyond, especially for grassland management, because in China there has been very little research on compensation compared to forest and other environmental resource protection (Chen and Wang 2006).

\section{ACKNOWLEDGMENTS}

The authors acknowledge the valuable comments of the two anonymous referees and Lynn Huntsinger (Associate Editor). We are also thankful to Yong-Yang and Zhen-Wei Ren for help in a previous questionnaire survey. This work was partly supported by Grant 91125019 from the State Natural Sciences Foundation of China.

\section{LITERATURE CITED}

Ambastha, K., S. A. Hhssain, and R. Badola. 2007. Social and economic considerations in conserving wetlands of indo-gangetic plains: a case study of Kabartal wetland, India. Environmentalist 27:261-273.

Akiyama, T., AND K. KawamuRA. 2007. Grassland degradation in China: methods of monitoring, management and restoration. Grassland Science 53:1-17.

Barnthouse, L. W., and R. G. Stahl. 2002. Quantifying natural resource injuries and ecological service reductions: challenges and opportunities. Environmental Management 30:1-12.

Bu, H. Y., Q. J. Ren, and X. L. Xu. 2006. Seed germinating characteristics of 54 gramineous species in the alpine meadow on the eastern Qinghai-Tibetan plateau. Acta Phytoecologica Sinica 30:624-632. (In Chinese)

CAO, J. J. 2006. Estimating on the value of services and damages and restoration of Maqu grassland ecosystem [thesis]. Lanzhou, GS, China: Lanzhou University. 29 p.

CaO, J. J., Y. C. XIOng, J. Sun, W. F. XIong, And Z. D. Guo. 2011. Different benefits of multi- and single-household grassland management patterns in the Qinghai-Tibet plateau of China. Human Ecology 39(2):217-227.

CaO, J. J., Z. W. Ren, Y. Yang, and Z. Z. Guo. 2008. Using CVM to estimate the restoring cost of Maqu grassland. Acta Ecologica Sinica 28:1872-1880. (In Chinese)

Carson, R. T., N. E. Flores, and N. F. Meade. 2001. Contingent valuation: controversies and evidence. Environmental and Resource Economics 19:173-210.

Chen, Z. Z., AND S. P. Wang. 2006. A discussion on the mechanism of reparation for balancing rangeland ecology. Acta Agestia Sinica 14:1-8. (In Chinese)

CLements, F. 1916. Plant succession. Washington, DC, USA: Carnegie Institution. 512 p.

Cuena, C. E., A. García-Gallego, and N. Georgantzís. 2004. An experimental validation of hypothetical WTP for a recyclable product. Environment and Resources Economics 27:313-335.

Cuperus, R., M. Bakermanns, H. A. De Haes, and K. J. Canters. 2001. Environmental Management 27:75-89.

Du, G. Z., AND Z. Z. Hul. 2001. Protection of alpine meadow resources in Gannan and the research of its optimal utility pattern. Journal of Lanzhou University 37:82-87. (In Chinese)
Dupont, D. P. 2003. CV potentially active and passive embedding effects when there are active users of environmental goods. Environmental and Resource Economics 25:319-341.

ELLIS, J. E., AND D. M. SwIF. 1988. Stability of African pastoral ecosystems: alternative paradigms and implications for development. Journal of Range Management 41:450-459.

Epstein, R. A. 2003. The regrettable necessity of contingent valuation. Journal of Cultural Economics 27:259-274.

GaO, X. C., A. Y. Jiang, AND J. M. LI. 2004. An institutional explanation of "over grazing" and institutional design of a control system. Journal Lanzhou University 32(4):116-120. (In Chinese)

Hallu, A., W. L. Adamowicz, and P. C. Boxall. 2000. Complements, substitutes, budget constraints and valuation application of a multi-program environmental valuation method. Environment and Resource Economics 16:51-68.

Hanemann, W. M. 1991. Willingness to pay and willingness to accept: how much can they differ? The American Economic Review 81:635-647.

JoHNSON, L. T. 2006. Distributional preferences in contingent valuation surveys. Ecological Economics 56:475-487.

LI, S. H., AND D. S. TANG. 2009. Study on ecological compensation policy among the micro subjects on water energy resources development. Journal Water Resource and Protection 1:10-15.

LIU, G. H., J. Wan, H. Y. Zhang, and L. J. Cal. 2008. Eco-compensation policies and mechanisms in China. Review of European Community \& International Environmental Law 17:234-242.

LIU, Z. H., J. M. YANG, AND Z. C. YANG. 2002. The present situation of eco-environment degradation counter measures in Maqu County Gannan. QingHai Prataculture 11(4):35-38. (In Chinese)

Long, H., L. Q. MAO, AND Z. X. Ju. 2006. Impact on water resources in Yellow River with climatic change. Journal of Water Resources and Water Engineering 17(4):74-77. (In Chinese)

MA, M. J., X. H. Zhou, And Z. D. Guo. 2010. Role of soil seed bank along a disturbance gradient in an alpine meadow on the Tibet plateau. Flora 205:128-134.

Maharana, I., S. C. Ral, and E. Sharma. 2000. Environmental economics of the Khangchendzonga National Park in the Sikkim Himalaya, India. Geojournal 50:329-337.

Noonan, D. S. 2003. Contingent valuation and cultural resources: A meta-analytic review of the literature. Journal of Cultural Economics 27:159-176.

Nunes, A. L. D., C. J. M. Jeroen, and D. Bergh. 2004. Can people value protection against invasive marine species? Evidence from a joint TC-CV survey in the Netherlands. Environmental and Resource Economics 28:517-532.

Ren, H., W. J. Shen, and X. Y. Wen. 2007. Degraded ecosystems in China: status, causes and restoration efforts. Landscape Ecological Engineering 3:1-13.

Shechter, M., B. ReIser, and N. Zalsev. 1998. Measuring passive use value-pledges, donations and CV responses in connection with an important natural resource. Environmental and Resource Economics 12:457-478.

Veisten, K., H. F. Hoen, and J. Strand. 2004. Sequencing and the adding-up property in contingent valuation of endangered species: are contingent non-use values economic values? Environmental and Resource Economics 29:419-433.

Wang, S. P., L. C. Song, Y. X. Han, And G. Y. Fen. 2006. Impacts of climate change on ecological environment in Maqu grassland, Gansu. Journal of Glaciology and Geocryology 28:556-561. (In Chinese)

WhitTINGTON, D. 2004. Ethical issues with contingent valuation surveys in developing countries: a note on informed consent and other concerns. Environmental \& Resource Economics 28:507-515.

Wierstra, E., P. Geurts, and A. Veen. 2001. Validity of CVM related to the type of environmental good: an empirical test. Integrated Assessment 2:1-16.

WILLS, K. G. 2002. Iterative bid design in contingent valuation and the estimation of the revenue maximizing price for a cultural good. Journal of Culture Economics 26:307-324.

Xu, Z. M., G. D. Cheng, and Z. Q. Zhang. 2003. Applying contingent valuation in China to measure the total economic value of restoring ecosystem services in Ejina region. Ecological Economics 44:345-358.

ZHANG, J. Q. 2007. Ecological supplementary mechanism and the coordinated regional development. Journal of Lanzhou University 35(3):115-119. (In Chinese)

Zhou, J. X., Z. H. Pen, and S. M. Fel. 2007. A discussion on compensation of forest ecological engineering benefit. Journal of Forestry Research 18:157-164. 